\title{
新加坡和纽约特色风貌地区规划管理经验及对深圳的启示
}

\section{The Experiences of Urban Planning Management in Singapore and NYC Identity Areas, and Enlightenment for Shenzhen}

摘要: 独特的城市文化与特色风貌是建设优秀城市的重要支撑 维度, 在全球化建设空间趋同的趋势下发掘和保持城市的地方 性, 对提升城市竞争力意义重大。新加坡和纽约是两个典型的 具有多元文化和独特风貌的国际城市, 其本土文化和特色风貌 的留存得益于及时建立了特色风貌保育体系, 并通过有效的技 术手段、管理手段、差异化的管理政策进行精细化的管控引导。 深圳处于全面进入二次开发的存量规划阶段, 目前保护制度的 缺位、对具有风貌价值的地区认同感不足以及管理技术的不完 善, 对整个城市特色产生的外部影响已不容忽视, 因此本文总 结新加坡和纽约的成功经验, 为深圳建立风貌保育体系和管理 策略提供有益参考。

Abstract: The unique culture and urban features are necessary to be a famous city. It is significant to maintain the city's local identity under the trend of the convergence of globalization. And it benefits to improve the competitiveness of the city. Singapore and New York are two typical international cities with diverse cultures and unique features. It should be attributed to the urban planning guidance such as effective technical methods, programmed management and different policy for the identity areas during the process of redevelopment. At the moment, Shenzhen is in full access to the redevelopment period. The lack of protection oriented management, regional and the imperfect technology method in the valued area has really influenced the urban features. So this article summarizes the successful experience of Singapore and New York, which can provide useful reference for Shenzhen to set up the identity area conservation system and urban planning management strategy.

关键词: 城市风貌; 特征地区; 规划管理; 经验; 纽约; 新加坡; 深圳

Keywords: Urban Features; Identity Area; Urban Planning Management; Experiences; New York; Singapore; Shenzhen

作者: 刘冰冰, 硕士, 高级规划师, 深圳市城市规划设计研究院 城市设计一所副所长、主任工。liubb@upr.cn

王泽坚, 硕士, 教授级高级规划师, 中国城市规划设计研究 院深圳分院副院长

\section{引言}

在全球化和国际化过程中，城市建设同质化现象日趋严重，因 此如何发掘和维持城市的地方性, 对具有差异化、特色化、富有人 文精神、承载本土生活特征的空间载体和特色风貌地区进行挖掘和 保护显得十分重要。

深圳的快速发展和城市建设是中国建城史上的奇迹, 但相比 于纽约的先锋与经典、上海的外滩腔调和弄堂故事、巴黎的艺术古 典与现代时尚, 年轻的深圳所展现的风貌特征中以现代化城市中常 见的高层楼宇为主导, 而能够传承和孕育历史文化、人文内涵、彰 显城市气质与传统生活特色的多元空间载体较为缺失。据深圳地名 志统计的古村数量来看, 从1 1984 年的 1500 个, 减少到 1992 年的 1200 个、2012 年的 200 个, 以每个月平均 4 个的速度在消失的古 村落, 目前原特区内仅剩下不到 20 个 ${ }^{[1]}$ 。具有历史价值的风貌特 色地区, 由于保护欠佳和低劣使用, 日渐破败, 孤立废弃, 居民拆 除重建意愿强烈。而这些老旧地区容积率低、拆除重建回报率高, 也激发了强烈的再开发意愿。随着深圳土地资源紧缺步人存量发展 时代, 2009 年城市更新办法实施, 2012 年颁布《深圳市城市更新办 法实施细则》中, 涉及到风貌保护的条文仅有两处, 分别是 : “第 十二条（二）：城市更新单元不得违反……历史文化遗产保护区（紫 线）等城市控制性区域管制要求” 和 “第十五条（五）：推进文化 遗产融人城市发展，保护城市肌理和特色风貌。”其内容的保护管 理对象仅限于紫线划定范围，对不属于历史保护街区、历史建筑的 其他特色风貌地区缺少相应的管理规定和规划引导, 也使得市场为 主体的城市更新在资本驱使下, 其主要方式为拆除重建而非有机更 新, 改造后形成了高度同质化现象。小地块、高密度、综合体成为 更新的主旋律, 根据 2013 年数据统计, 当时深圳超过百万平的城 市更新综合体就有 16 个。2010-2015 年间, 深圳规划和国土资源 委员会共审批通过更新专项规划 249 项, 其中 $95 \%$ 以上为拆除重 建项目, 2016一-2020 年深圳将推动城市更新项目达到 551 个, 是上 
一个五年的一倍以上。按照正在编制的《深圳历史风貌区和 历史建筑保护规划》的评价体系统计来看, 被列人历史风貌 保护区线索地区中有 12 处更新单元已获批, 更新类型为拆 除重建; 1 处正在审批过程中; 另有 10 处已被列人更新单元 计划（截至 2016 年 7 月）。除了城市更新拆除重建的影响, 由于缺少对现存建筑的维护和修缢等相关机制, 导致一些具 有典型特征的旧居住区逐渐老旧、环境破败、设施难以更新, 其空间风貌的价值也在慢慢降低, 未来仍存在被拆除重建的 隐忧。可见，保护制度的缺位、对具有风貌价值的地区认同 感不足以及管理技术的不完善, 对城市特色风貌地区的留存 所产生的外部影响已不容忽视, 一些能够反映城市发展历程 和集体记忆, 具有社会、人文、场所等内涵的公共价值地区 将加速消失, 特色风貌保护体系建立迫在眉睫 ${ }^{[2]}$ 。

独有的文化与风貌是建设全球城市的重要支撑维度, 其 不仅为城市的外在景观增添魅力, 更重要的是多元的空间以 及其衍生的多样文化更加有助于聚集人才, 从而为城市经济 发展、技术创新提供有力支持。纽约、新加坡、香港、上海 等全球国际城市无不在全球化席卷下空间趋同的浪潮中保持 清醒, 为避免资本市场对多元文化和风貌的侵蚀, 对值得留 存的风貌地区进行规划管理和发展引导, 进而在市区重建的 过程中避免大拆大建。精细化的规划管理在地方特色保育、 独有内涵挖掘、历史文脉传承等方面发挥了积极的作用。

\section{1 新加坡历史风貌地区管理及经验}

\section{1 新加坡特色风貌地区概述}

纵观新加坡的城市规划及管理, 当前管理体系中对具 有本土特色风貌并进行规划管理的地区主要指 “保育地区”

(conservation area)。这一类地区的保护对象和内涵并不是 从初始建立至今一成不变的, 而是随着新加坡城市发展战略 的转变而不断扩展和延伸, 从狭义的 “历史保护地区” 逐步 扩展为广义的 “对本土文化和特色风貌具有重要价值的更广 泛地区”。

自 1960 年代独立以来, 新加坡先后经历了自身快速城 镇化、世界全球化等多个重大发展时期, 城市发展日新月 异。最初十几年城市的飞速建设使得具有往昔风采的建筑和 城市风貌地区在发展进程当中濒临消失。然而新加坡当局较 早的意识到, 旧时代的建筑及地区不仅仅是有着商业旅游价 值的历史遗迹, 更是国家地区自身认同感的根本来源。因此, 从 1970 年代, 政府开始着手通过运用规划手段和立法制度 来保护旧时代遗迹在城市开发过程中的风貌延续和留存, 并 于 1989 年里程碑式地建立了 10 个保育地区, 随后逐年增加, 包括历史区 (historic district)、别墅历史区 (residential historic district)、次住宅区 (secondary settlement)、洋房 (bungalow)、 遗迹建筑（heritage structures）以及其他类型地区。针对不同 类型保育地区的保护及再开发, 新加坡都市重建局 (URA) 制定了以保育地区开发设计导则 (Conservation Guideline) 为 主的详细要求, 以及严格的申请开发程序。此时, 保育地区 的保护对象以具有一定历史价值和时间年限的建筑物、建筑 群为主。

2001 年之后新加坡历史风貌保育的对象不再局限于以建 成时间为衡量标准的历史建筑、历史街区, 其管理内涵也由 “保护” (即简单的保留和修复) 逐渐转变为 “保育” (活化利 用旧有建筑并培育和激发活力), 这一观念的转变始于 2001 年 编制的概念规划 (concept plan)。其中 “注重认同感和地区的 特色” 是迈向新世纪的新加坡首次并着力提出的规划思想 ${ }^{[3]}$ 。 2003 年, 为了落实概念规划提出的要求, 发掘、保留、增强 城市中部分地区的独特性, 留存新加坡在不断城市化和国际化 进程中日渐消失的旧日氛围和自然风貌, 提高城市的吸引力, 建设一个独具风格、获得广泛认同感的国际城市, 新加坡市区 重建局组织编制《特征规划研究》(Identity Plan)。在该规划中 提出保留 15 个富有特色的区域, 这些地区所需保留标识特征 的侧重点各不相同, 或是具有独一无二的街道景观, 或是有 丰富而有价值的特色建筑, 或是维系着当地社区某种精神生 活的特定区域。具体包括魅力老街 (Old World Charm)、城中 村 (Urban Villages)、南部山脊和山坡村庄 (Southern Ridges \& Hillside Villages)、纯朴海岸 (Rustic Coast), 后续的几年中又不 断增加了三个有特色的节点地区（表 1)。

特征规划的建议性内容最终均被转化为导则 (例如对周 边新增建筑物的管理、对功能的引导、增加公共空间等内容) 纳人全面规划中进行管理, 有些地块还因此修改了全面规划 的土地使用性质。虽然特征规划所确定的保育地区的类型、 衡量标准与当时既有规划管理中保育地区不太一致, 但其广 义内涵和管理方式较为相似, 因此后来这类地区均被纳入保 育地区进行统一规划管理。至今, 新加坡的保育地区已增至 100 多个, 实行 “划线管理” 和 “动态准人制度”, 都市重 建局对于这些地区开发的管控和发展引导对新加坡维系本土 特色风貌起到了突出的作用, 并对新加坡能够跃升成为国际 知名的多元文化城市具有重要的意义。

\section{2 新加坡保育地区的规划管理}

为了便于有意图参与保育地区开发建设的开发者查询信 息和实行更为公开的规划管理, 都市重建局以信息备注的形 式将全部管理要求链接到划有保育地区范围的电子信息地图 上, 以提供动态指引。在新加坡都市重建局网站上可以查询 到保育地区的管理要求, 主要包括规划设计导则和开发程序 两个部分, 对于特殊的地块还会辅之以相应的管理政策。同 
时, 市区更新局还制定保护技术宣传册等相关的保护原则及 技术指引指导规范保育地区的保护及再开发活动。

\subsection{1 规划设计导则要求}

新加坡现有规划体系采用二级规划编制体系: 概念规划 (类似战略规划与总体规划) 以及全面规划 (类似于法定图 则、控制性详细规划), 全面规划直接指导地块开发, 其中全 面规划是新加坡唯一的法定规划。保育地区的保护导则、城 市设计导则在全面规划的控制性规划的“街区规划、城市设计、 保育地区及历史遗迹控制图则” 中被提出, 并赋予了法定地位。

大部分保育地区的再开发仅需遵守《保育地区开发设计 导则》(Conservation Guideline), 而一些特殊保育地区（特 别是位于中心地区) 的规划设计导则由 “保育地区开发设计 导则” 和 “控制图则” 共同组成。其中, 保育地区开发设计 导则从建筑物保护修复及历史价值留存的角度提出相应的管 控要求, 而控制图则是从城市设计价值领域中城市公共利益 的维护、片区活力激发、片区风貌协调以及步行体验等角度 提出相应的管控要求。

新加坡的法定规划编制均由都市重建局承担, 但在保育 地区则尤其重视公众参与的环节, 在导则编制过程中会咨询 专家学者保护顾问、保育地区建筑的产权所有者、专业研究 小组等多方人士, 以获得更为广泛和全面的指导意见 (图 1)。

不同的地区会根据实际情况量身定制导则, 并从导则 手册中抽取相应需要遵循的条款。以甘榜格南 (Kampong Glam）街区为例, 它是新加坡官方划定的四大历史价值保留
区之一。该区域由于是历史价值保留区, 又同时拥有洋楼、 历史遗迹等其他类型保护对象, 因此其导则包括了针对历史 价值保留区、洋楼、历史遗迹等多类条款要求（表 2, 图 2); 同时, 该地区还必须遵守中心区的控制图则中相应的导则要 求 (图 3)。

\subsection{2 开发程序要求}

正常地块建筑开发申请程序是 : 首先, 由具有资质的注 册建筑师（或注册咨询师或高级工程师）通过市区重建局的 建设及房地产电子申请系统—CORENET ess 申请建造项 目规划许可; 其次, 得到许可后, 可视项目具体情况再申请 其他批准, 手续齐全后可开发。通常, 项目所需批准都可通 过该系统申请, 如, 建设计划批准、临时占用许可、消防安 全证书、法定竣工认证。

当申请开发项目位于保育地区内时, 除建造项目规划许 可等证书外, 还需申请保护许可。此类情况适用于对保护区 内部建筑的修复工作、新建及改动工作, 或者改变原有建筑 用途等情况。在保护区内工作必需遵从保护方针, 且必须在 保护许可失效前完成。市区重建局特别要求, 在提交保护工 作时, 提交内容必须有注册建筑师及高级工程师提供的专业 意见及帮助。除必须申请保护许可外, 如需对保护建筑进行 新建改动活动或更改用途则另有相关规定办法。

\subsection{3 开发模式和政策激励}

新加坡政府为了鼓励社会资金积极参与保育地区的再开

表 12003 年新加坡特征规划中提出的特色区域（部分）一览表

\begin{tabular}{|c|c|c|}
\hline 名称 & 地区特色和目标 & 地区景观 \\
\hline $\begin{array}{l}\text { 惹兰加由 } \\
\text { Jalan Kayu } \\
\text { (美食街) }\end{array}$ & $\begin{array}{l}\text { 惹兰加由因其舒适的环境和各式各样的美食吸引了来自全国各地的人们, 其中最出名的就是美味烤肉煎 } \\
\text { 饼。在未来的几年里, 这一区域将在保留自身独特特征的同时, 通过环境改善优化游客的感知和体验 }\end{array}$ & \\
\hline $\begin{array}{l}\text { 魅力老街 } \\
\text { Old World Charm } \\
\text { (特色建筑) }\end{array}$ & $\begin{array}{l}\text { 这一地区是在 } 1920 \text { 年代一1950 年代间, 新加坡市中心向东扩张时发展起来的。如今, 这里继续着它 } \\
\text { 的热闹街区生活, 独特的街景和丰富的建筑 }\end{array}$ & \\
\hline $\begin{array}{l}\text { 实龙岗花园 } \\
\text { Serangoon Garden } \\
\text { (1950 年代特色居住区) }\end{array}$ & $\begin{array}{l}\text { 实龙岗花园是一个 } 1950 \text { 年代建立的私家屋苑。如今, 实龙岗花园的圆形广场被著名的忠忠 (chomp } \\
\text { chomp) 美食广场和数不胜数的餐饮店环绕, 圆形广场和红色屋顶是其独特的特色标志 }\end{array}$ & \\
\hline $\begin{array}{l}\text { 山坡村庄 } \\
\text { Hillside Village } \\
\text { （游览目的地） }\end{array}$ & $\begin{array}{l}\text { 多年以来, 随着新加坡各界人士的前来, 南部的山脊已经成为了一个非常受欢迎的目的地。10 km 的 } \\
\text { 铁索连接着山丘使人们得以欣赏到城市的全景, 同时在绿意中享受宁静。当地的小食店和艺术画廊, } \\
\text { 山脚下古朴的吉尔曼 (Gillman) 村庄和摩士 (Morse) 路让这里带来了不一样的体验 }\end{array}$ & 8 \\
\hline
\end{tabular}

资料来源 : 作者整理自 https://www.ura.gov.sg 


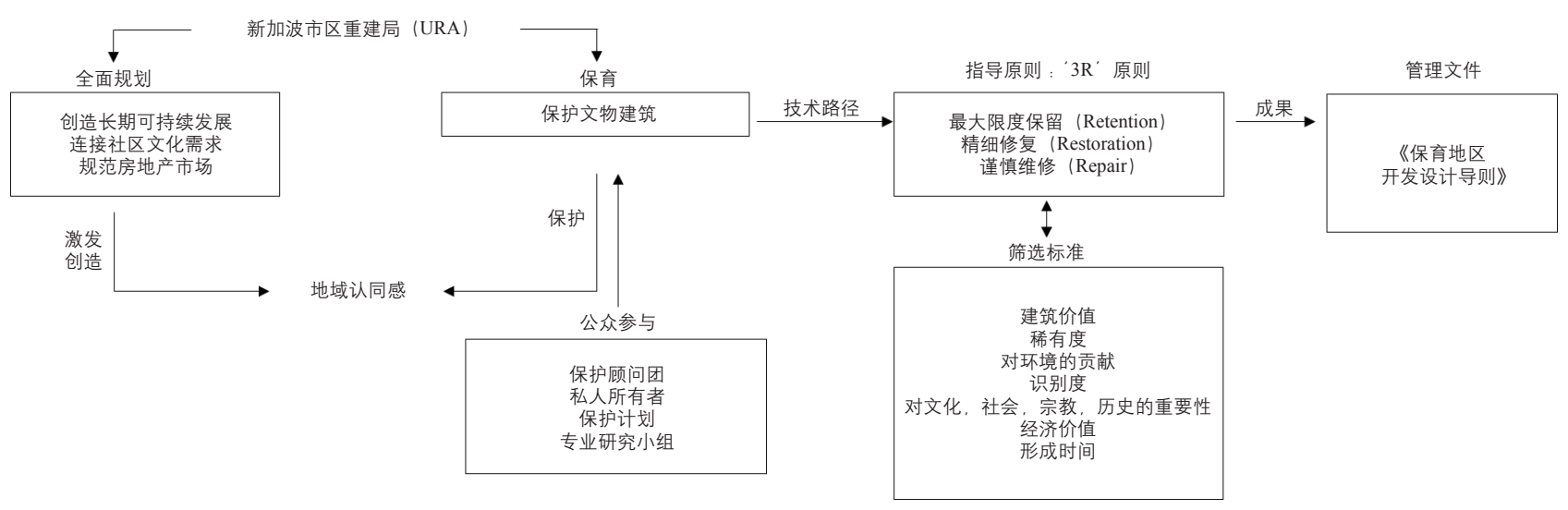

图 1 保育地区开发设计导则制定路径 资料来源 : 作者翻译整理自参考文献 [4]

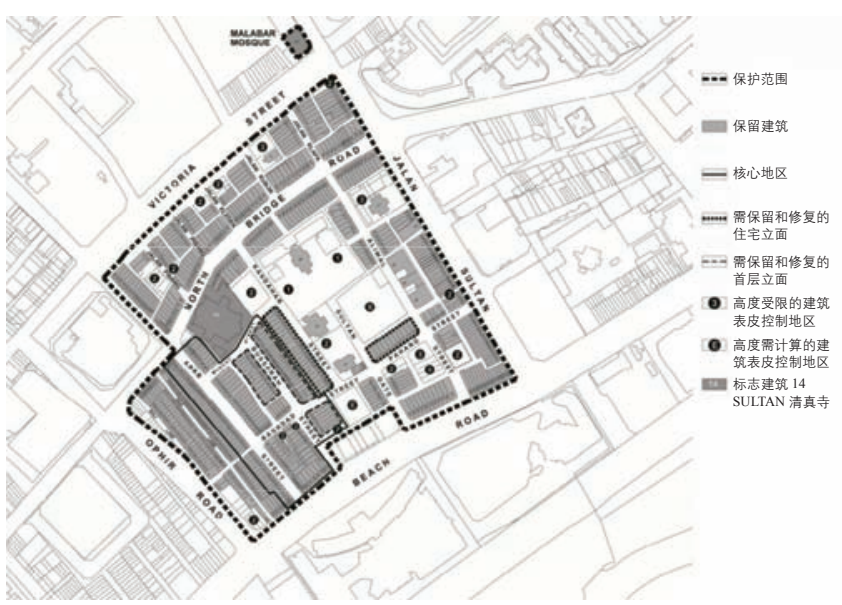

图 2 甘榜格南地区保护规划图则

资料来源 : https://www.ura.gov.sg/maps/\#

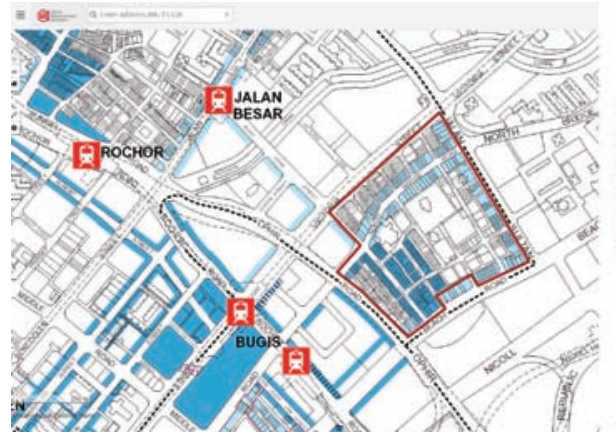

活力激发用途规划

E地下窒活力激发范围 (强制) 地下室活力激发范围 (鼓励) 建筑一楼活力激发区域( 强制) $\square$ 建筑一楼活力激发区域( 鼓的) E建筑二楼活力激发范围( 强制) 四建筑二楼活力激发范围(鼓的)

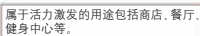
经双威机构认定后, 以下用途也可以

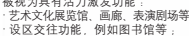

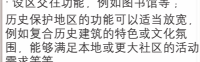

图 3 甘榜格南地区控制图则一一活力激发用途规划 资料来源 : http://www.ura.gov.sg

\section{表 2 甘榜格南地区适用的保育地区开发设计导则条款及受控要素}

\begin{tabular}{|c|c|c|}
\hline \multicolumn{2}{|c|}{ 适用导则 } & 受控要素 \\
\hline \multirow{3}{*}{$\begin{array}{l}\text { 保育地区 } \\
\text { 开发设计 } \\
\text { 导则 }\end{array}$} & $\begin{array}{c}\text { 历史价 } \\
\text { 值保留 } \\
\text { 区导则 }\end{array}$ & $\begin{array}{l}\text { 规划受控要素主要根据该地区保护规划及全面规划确定, 要求甘榜格南区域内划定在核心区内建筑必须将一楼作为具有活力激发的功能, 如 } \\
\text { 商业餐饮等。其次, 区域内建筑高度必须保持现有高度, 建筑地上外观必须维持原样。修复受控要素主要根据 “3R” 原则确定, 主要对屋顶、 } \\
\text { 房屋前院、建筑外观、附属建筑、五脚基 (骑楼)、山墙、共用隔墙、制冷管道等主要建筑要素及电器组件有明确的设计、位置、建筑材料 } \\
\text { 以及软装材料的要求 }\end{array}$ \\
\hline & $\begin{array}{l}\text { 洋房控 } \\
\text { 制导则 }\end{array}$ & $\begin{array}{l}\text { 规划受控要素主要根据该地区保护规划及全面规划确定, 主要要素有建筑用途、容积率、更新拓建（新建区退界、新旧连接区域融合、新旧 } \\
\text { 建筑连接）、保护区新建等。 } \\
\text { 修复受控要素主要根据 “3R” 原则确定, 主要对房顶、建筑外观、附属建筑、楼层、楼梯、房屋内饰、建筑色彩、抽风机、空调等主要建筑 } \\
\text { 要素及电器组件有明确的设计、位置、建筑材料以及软装材料的要求 }\end{array}$ \\
\hline & $\begin{array}{l}\text { 外墙控 } \\
\text { 制导则 }\end{array}$ & $\begin{array}{l}\text { 外墙控制主要针对在保护区内的非保护建筑, 分为与保护建筑相邻建筑, 与保护建筑不相邻建筑。若该类建筑在历史保护区核心区内则遵循 } \\
\text { 一楼用于更新作商业餐饮用途的规定。新建建筑则建筑风格必须与原街坊一致。 } \\
\text { 新建筑或修复要求设计师遵循街区风格稳定和谐的准则, 导则对一般主要建筑要素及电器组件有明确的设计、位置、建筑材料以及软装材料 } \\
\text { 的要求及建议 }\end{array}$ \\
\hline \multicolumn{2}{|c|}{ 指示牌导则 } & $\begin{array}{l}\text { 在保护区内, 传统指示牌不允许被修改, 临时指示牌通常使用塑料材质, 特定的色彩, 允许为临时活动做的金属或布质指示牌。对正门院墙、 } \\
\text { 正门外表 (商铺住宅、骑楼、一楼圆柱等)、山墙、后墙上的指示牌都有较为详细的位置和大小的规定 }\end{array}$ \\
\hline \multicolumn{2}{|c|}{\begin{tabular}{l|l} 
禁止新增餐饮区域 \\
划定
\end{tabular}} & $\begin{array}{l}\text { 被维多利亚街 (Victoria Street)、拉惹苏丹（Jalan Sultan）、海岸路（Beach Road）和奥菲亚路 (Ophir Road）所包围的区域不允许在店铺内新 } \\
\text { 增餐饮 }\end{array}$ \\
\hline \multicolumn{2}{|l|}{ 特殊规定 } & 应遵守巴梭拉 (Bussorah) 街道沿街商铺外观设计导则, 在该区域内的商铺必须保持现有一楼商铺外观不得改变 \\
\hline
\end{tabular}

资料来源 : 作者根据 https://www.ura.gov.sg 网站相关内容整理 
发活动, 会依据不同地区及开发项目的具体情况给予不同的 优惠政策, 如 : 允许保护区内合理新增建筑 (必须符合设计 导则要求) ; 免除停车位缺额费及发展税、放宽道路扩展界 限的要求以及政府帮助建设基础设施和完善公共事业、“新 旧相容”捆绑开发等政策。其中代表性案例是 1996 年中华 广场 (Chinasquare) 在商业中心区旁融合和新旧建筑的案 例。市区重建局在一处 16 层办公楼地块拍卖中, 刻意将 19 间街屋一同纳人该幅土地, 并设定相应的土地出让条件, 由 私人开发商进行修复和再开发。该发展商对街屋内部进行改 造以适合新的发展用途, 同时对街屋外观和新建建筑的外观 进行了很好的融合, 取得非常好的效果。另外, 新加坡对全 市的建筑物维护修缮进行法令化管理, 《物业管理法》规定 每五年对整幢楼房的外墙、公共走廊、楼梯、屋顶及其他公 共场所进行依次维修, 也促进了新加坡的整体风貌维护。

\section{3 小结}

新加坡的城市风貌保育地区在定义保护对象方面, 已不 再局限于传统历史建筑的保护, 而是逐步拓展至对特色地区 整体风貌的保护, 并将历史保育地区和特征地区进行合并管 理, 扩大后的保护类型不仅保留了新加坡地区历史发展的印 记, 还大幅度避免了城市景观经受拆建循环最终可能呈现的 趋同性, 避免城市在快速发展过程中中失去标识度及其历史 特征。在保育规划管理方面, 主要从规划设计导则、开发申 请程序以及特殊政策的制定三个方面进行引导和管控, 其中 特别强调发挥城市设计在保育地区更新再开发方面的突出作 用, 确保地区特色空间品质的维持及提升。

\section{2 纽约特色风貌地区管理及经验}

\section{1 纽约特定意图区概述}

1969 年, 为了避免纽约各区同质化、标准化发展, 纽 约城市规划委员会将具有特色风貌特征的区域划定为特定意 图区 (special purpose district), 并在这类地区强调 “城市设 计” 和 “开发政策” 的引导 (图 4)。与纽约历史文化遗产地 区 ${ }^{1}$ “严格的人选审查要求、以保护为主的管控策略以及实 行标准严格的规划管理” 有所不同, 这类地区往往没有建设 年限的严格要求, 其中最初设立的特定意图区的划定意在保 护该地区的特色风貌和当地氛围, 如格林威治村 (Greenwich Village)、布鲁克林高地景观区 (Brooklyn Heights Scenic View District)、小意大利地区 (Little Italy District) 等, 而陆续增
加的一些特定意图区则意在为促进片区的开发而制定相应的 特殊政策，例如在威廉斯堡绿点（Greenpoint-Williamsburg） 地区为鼓励和促进投资，允许工业用地中混合居住功能以及 提高某些地区的发展密度等等, 与城市特色风貌保护或历史 文化保护并无直接关联。

特定意图区依据特定意图区的特色及数量, 可分为一般 特定意图区和非一般特定意图区。其中，一般特定意图区是 指在全市范围内, 属于加强商业氛围地区 (EC)、限制商业 发展地区 ( LC) 、混合用途地区 (MX)、自然景观地区 (NA)、 保护社区 (PC) 及特殊风景地区 (SV) ; 非一般特定意图区 则是指在全市范围内, 拥有独一无二的景观或建筑等特点的 特定意图区，如小意大利区（LI）、林肯中心区（L）等。从 1969 年设立特定意图区以来, 共计 68 个地区被纳人管理。

\section{2 特定意图区的规划管理}

纽约的特定意图区与历史保护区/地标是两套分开的管 理体系, 前者由纽约城市规划委员会管理, 后者由纽约名胜 古迹保护委员会管理。由于特定意图区没有固定的划分及鉴 定标准，而是通过对地区本身风貌特色的价值认知或特殊发 展意图而发起的管理机制，纽约规划局、议员、各区政府 部门均可提出特定意图区提案, 并由纽约城市规划委员会 (CPC) 审议, 审议通过后即可纳人管理体系。但如果申请 区域内含有历史街区或地标为由申请特定意图区, 则必需经 由纽约市名胜古迹保护委员会认证通过再递交给城市规划委 员会审批通过 ${ }^{[5]}$ 。

特定意图区设计导则的管控要素因地区特色不同而有 所差异, 但大都是通过城市设计研究来确定相应的管控要素 和具体要求, 粗放的拆除重建是绝对不予允许的, 而是采用 功能活化、旧建筑再利用以及增加少量新建建筑的方式进 行再开发。城市设计导则在这些片区的开发项目中发挥了 重要的引导作用。以具有建筑特色的典型居住风貌区克林顿 (Clinton) 地区为例, 其设立目的是为了保护有特色的居住 区，以及该区域内具有代表性的小众商业文化，控制新建筑 开发活动。该区域的设计导则 (图 5) 将该地分为三个部分, 保护区（preservation area）、周边区（perimeter area）以及其 他区域。保护区内的开发、拓展、延伸或者变更等建造活动 都必需遵循该地区的调控条例, 其中受管控的要素有楼层用 途、开敞空间、楼层高度及退界范围、停车场等。除此之外, 还针对克林顿地区内部特殊地区及周边边缘地区设立一系列

(1) 纽约的历史文化遗产地区由地标和历史保护区组成。一般来说, 作为地标必须有 30 年以上的历史, 还要有能够代表国家 (州/城市) 发展、历史、 文化的突出特点或历史美学价值。具体可以按照地标形式, 分为独立地标 (外表值得保护的建筑)、部分地标 (内部值得保护且向公众开放的 建筑或部分结构）以及风景地标（城市公园或其他景观）。而历史保护区则是指拥有显著的建筑及历史价值、具有独特个性的地区，或者是地 标所在地点或地区。该类地区以保护为主要发展策略, 其中涉及地标的保护最为严格。 
特殊管控要求。

另外一个典型的案例是具有意大利异域风情的小意大利 区保留了许多意大利的店铺和餐馆, 它的建筑形式和底层商 铺都十分具有当地的风貌特色。为加强这一地区特色, 设计 导则中鼓励新建建筑与原有建筑保持同样尺度规模, 维持道 路的适当尺度以保护传统邻里交往的街区生活, 鼓励增加公 共空间和行道树, 不允许拆除街区内有特色的建筑。此外, 除原有用地性质或建筑使用性质外，该地区可以通过设计研 究增加使用功能以提升地区的价值, 进一步促进片区的风貌 和活力。其城市设计导则的管控要素主要涉及用地管控（商 业工业现有用地管控、开发功能限制)、建筑物管控（容积率、 建筑高度、建筑类型、退界范围、建筑外观）、公共空间 管控（空间利用率、景观控制）、老旧建筑重新利用（停车 场、行道树等配套设备)。除此之外还有对哈德逊街（Huston Street)、桑树街 (Mulberry Street)、巴利街 (Bowery Street)、 科耐街 (Canal Street)、肯梅尔 (Kenmare Street) 等街道商 业功能、街道风貌的管控条款。

在城市设计导则的指引下, 规划委员为想要申请特定意 图区内地块开发的开发商或土地拥有者提供了较为简便的申 请渠道。通常情况下, 委员会委派具有资质的规划师帮助申 请者审核信息，在符合该特定意图区设计导则要求的前提下， 申请者可以直接向建设局（Department of Building）递交修 建申请, 不需要规划委员会审批; 当特定意图区和历史保护 街区/地标建筑二者范围有交叉或重叠时, 则首先认可由纽 约市名胜古迹委员会提出的历史保护街区/地标建筑管理要 求，再认可城市规划委员会制定的特定意图区分区规划设计 导则。因此, 申请者必须满足双重申请标准, 并向两个委员 会以及建筑部门递交项目申请, 批复成功后, 才可以进行开 发动工。

除此之外, 规划委员会还会针对有意开发的申请者提供 较为特殊的开发政策，包括在容积率、土地用途、保障房、 公共设施等方面允许不同于原规划的弹性范围及容量，用以

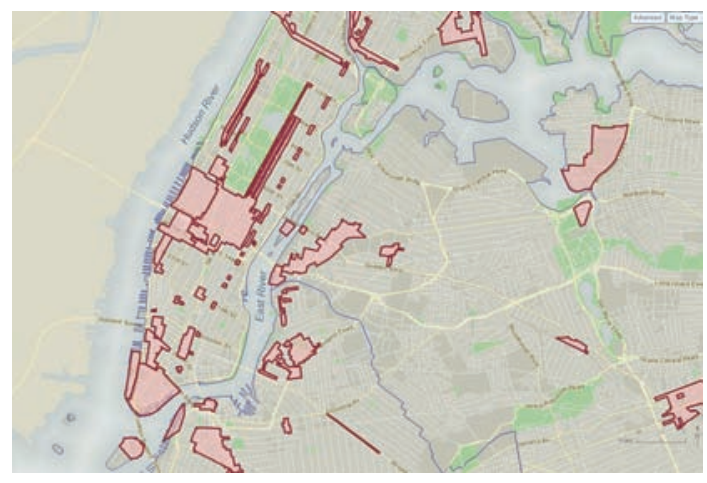

图 4 纽约特定意图区分布 (局部)

资料来源 : http://www1.nyc.gov
帮助平衡计划修建更新的开发商或所有人的利益收益, 力求 更好地推动特定意图区的建立与发展。

\section{3 小结}

纽约的特色风貌地区基本涵盖在历史街区/地标建筑以 及特色意图区两套管理体系管理范围内, 但分属于不同部门 进行管理。但与新加坡相似的是其管理手段 : (1) 对特色风 貌地区采用保育式的管理, 鼓励功能活化和建筑再利用, 不 允许拆除重建的再开发模式; (2) 在管理过程中城市设计起 到了突出的作用, 通过分别编制每一地区/街块的城市设计 来识别管控要素、制定管理要求, 而不是通则式的管理; (3) 城市设计导则具有法定效力, 在城市设计导则的引导下开展 城市更新工作；(4) 制定了相应的开发申请程序; (5) 为促 进片区的风貌保护和城市活力, 实行差异化的政策管理。

\section{3 对深圳的启示}

新加坡和纽约是两个典型的具有多元文化和独特风貌 的国际化都市, 其本土文化和特色风貌的留存得益于及时建 立了特色风貌保育管理体系, 将不属于狭义传统历史保护地 区的新时期城市风貌特征地区也纳人规划管理, 并通过有效 的技术手段、管理手段、差异化的管理政策进行精细的管控 引导。总结其经验, 对深圳建立特色风貌保育体系具有如下 启示。

一是应尽快建立深圳特色风貌保育体系。深圳全面进 人存量二次开发的发展阶段, 已经呈现出资本市场对城市本 土特色风貌的快速侵蚀并破坏严重的现象, 因此应尽快拓展 现有历史保护规划（即紫线控制管理）的范畴, 以动态的大 历史观为视角 ${ }^{[6]}$, 除历史街区和历史建筑之外, 还应尽快将 现存能够反映改革开放以来能够反映和记载一定时期发展记 忆、具有建筑风貌特征、承载特色文化内涵、提供特色生活

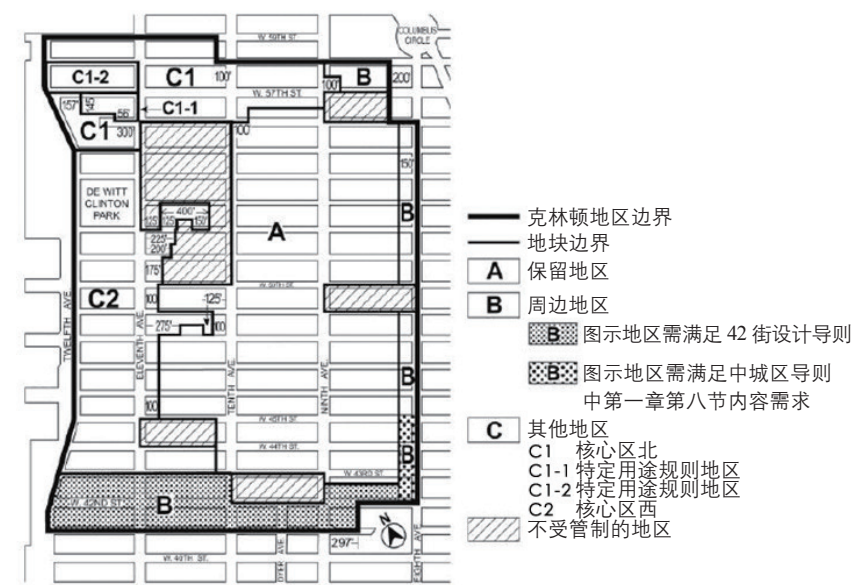

图 5 克林顿地区城市设计管控图则 资料来源 : http://www1.nyc.gov/assets/planning 
体验的地区纳人保护范畴, 例如有特色的城中村（如水围、 大望、大芬等）、工业遗产地区（如金威啤酒厂、光明糖厂、 光明猪场、浮法玻璃厂等)、特色居住区 (如百花小区) 、特 色混合社区 (如华侨城) 等纳人管理范畴, 并以物质空间为 载体, 重点突出其历史文化价值、城市机能、人文内涵、风 貌特色和功能活力。建立特色风貌保育区名录并制定相应管 理规定, 以划线的方式确定保育管理范围, 并实行动态准人 机制。

二是应倡导永续再生的有机更新模式。在特色风貌保 育地区应避免大拆大建, 而是秉承以人为本、尊重文脉、 回归生活、激发价值的理念, 保护重要建筑物、重要特征 场所、特色空间格局、街道尺度、社区氛围等, 通过公共 空间改善、建筑物改造修复、公共活动植人等手段, 探索 可持续再生的有机更新路径。有效控制更新成本, 营造更 多的低成本、多元化、个性化的创新孵化空间与创业空间、 特色文化创意空间、本土风貌感知场所以及有归属感、可 担负的城市生活环境。在守护城市核心价值与地方特色的 基础上, 以动态发展与精细化营造的方式来创新城市空间 供给模式。

三是增强空间管控与城市设计引导。加强街区层面城 市设计管理对特色风貌保育地区的管控和引导作用, 兼顾

“高质高量的空间增容”与 “本土风貌特征维系”, 改变以 往城市设计研究在城市更新单元规划中的辅助角色, 在特 色风貌保育地区由规划主管部门先行编制城市设计研究并 转化成城市设计导则, 通过行政审批赋予其法定管理地位。 经城市设计研究识别后确定管控和引导的相关要素, 并在 该阶段加强公众参与保障其可操作性。最终在城市设计导 则的指引下开展以市场为主导的更新单元规划, 加强空间 管控。

四是创新保护管理机制和配套政策。结合现有规划管理 制度制定特色风貌保育区的管理程序, 优化城市更新管理机 制, 限定并引导风貌保育区内的城市更新方式, 充分考虑公 众利益、尊重产权、坚持跨界合作和多方参与; 以试点的方 式探索特色风貌保育区的创新政策如 “容积率转移、权属转 移、用地兼容、地价税收、营业许可”等相关激励政策, 激 发市场参与热情, 保障实施者受益更多; 制定风貌保育区内 建筑物维护修缮的相关制度或专项基金。

\section{参考文献}

[1] 总体城市设计和特色风貌保护策略专项研究. 深圳市总体规划修编 2020-2030[R]. 2017.

[2] 城市空间, 深圳大学. 深圳历史风貌区和历史建筑保护规划 [R]. 2016.

[3] 孙翔, 汪浩. 特征规划指引下的新加坡历史街区保护策略 [J]. 国外城市 规划, 2004(6): 47-52.
[4] Kien T, Zhuo W C, Keng H C. The identity of a conserved housing estate in transition - the case of Tiong Bahru Singapore[D]. Singapore University of Technology and Design, 2014.

[5] The Rules of the City of New York[S]. New York Legal Publishing Corp, 2011.

[6]中国城市规划设计研究院深圳分院. 深圳历史风貌保护区和优秀历史 建筑保护规划 [Z]. 2011.

(本文编辑：许玫) 